\section{Quiz: Electrophysiology}

A 27-year-old patient with episodes of syncope and short episodes of documented tachycardia.

What is the possible cause of syncope?
1. Scar-related ventricular tachycardia

2. Atrial flutter with 1:1 conduction

3. Pre-excited atrial fibrillation

4. Antidromic AVRT

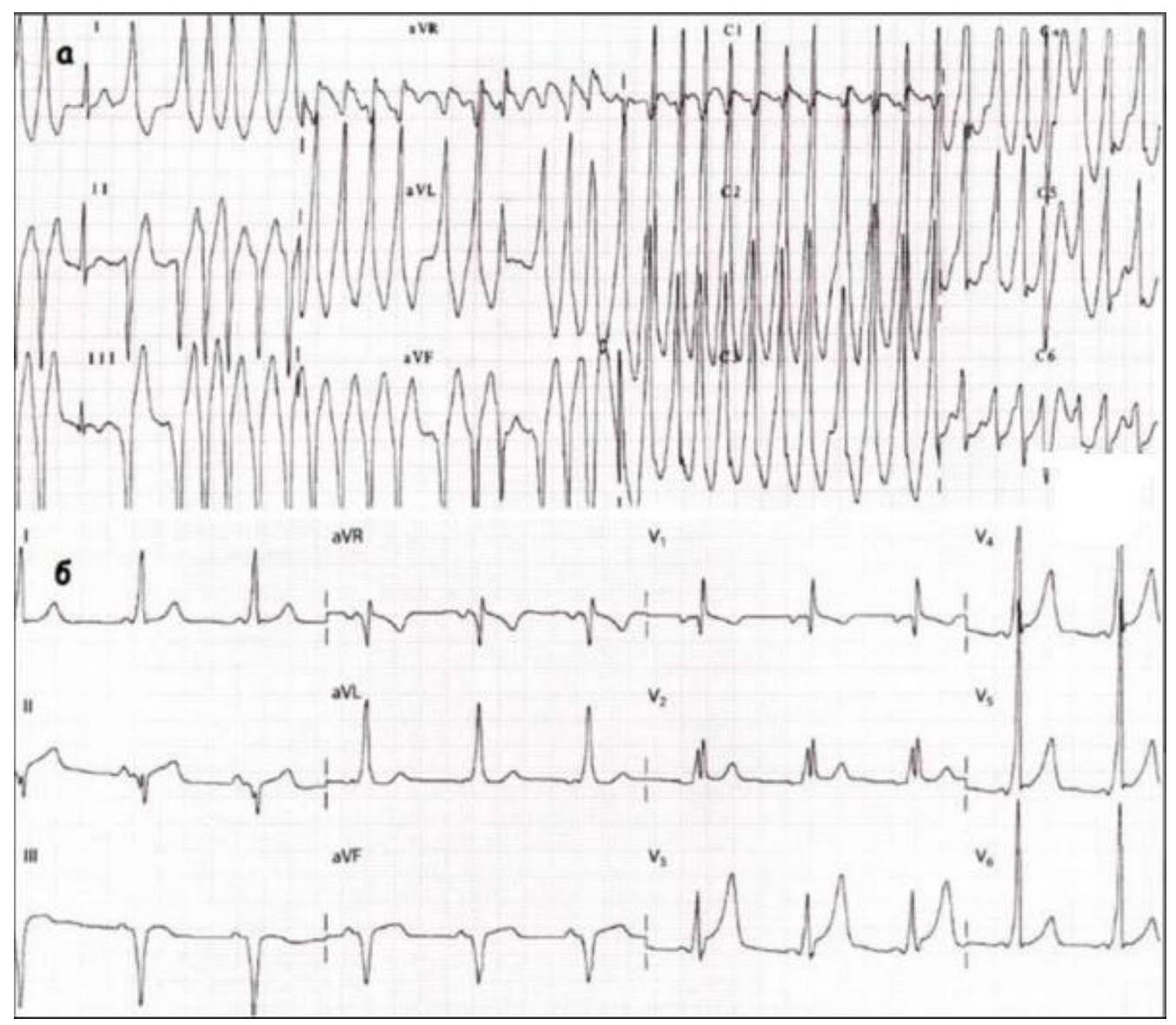

Figure 1. Electrocardiogram tracings

Ayan Abdrakhmanov, Zhandos Esilbayev Department of Interventional Arrhythmology National Research Cardiac Surgery Center Astana, Kazakhstan

Peer-review: Internal Authorship: A.A. and Z.E. equally contrıbuted to preparation of quiz Conflict of interest: None to declare Acknowledgement and funding: None to declare

Address for Correspondence: Ayan Abdrakhmanov, Department of Interventional Arrhythmology, National Research Cardiac Surgery Center Astana, Kazakhstan, Email: ayan-3@mail.ru

Received 24.01.2019 Accepted: 25.01.2019

Copyright $\odot 2019$ Heart, Vessels and Transplantation

doi: $10.24969 /$ hvt.2019.101 